\title{
FLIGHT OF THE EYE GNAT, HIPPELATES PUSIO (DIPTERA: CHLOROPIDAE): EFFECT OF TEMPERATURE, LIGHT, MOISTURE AND WIND VELOCITY ${ }^{1}$
}

\author{
By Reid R. Gerhardt and R. G. Axtell ${ }^{2}$
}

\begin{abstract}
The flight activity, based on collections from humans, of Hippelates pusio eye gnats was measured under varying field conditions. Thresholds for flight were $17^{\circ} \mathrm{C}$, $0.25 \mathrm{~mm} \mathrm{Hg}$ vapor pressure deficit (VPD), 5.38 milliphots (5 ft-c) of light and wind velocity below $67 \mathrm{~m} / \mathrm{min}$. Graphs are presented for flight activity at various values of temperature, light, VPD, and wind velocity.
\end{abstract}

Hippelates pusio Loew (Diptera: Chloropidae) is an annoying pest of man and animals in much of the southeastern United States. It is attracted to body secretions and wounds and has been implicated in the spread of conjunctivitis, anaplasmosis, and bovine mastitis (Dow \& Hines 1957, Roberts 1968, Sanders 1940). The major economic importance of this pest in North Carolina is annoyance in the recreation industry, especially on the golf courses of the Sandhills area where large populations are present from June to November (Axtell \& Edwards 1970).

Data on the effects of environmental conditions on the activity of Hippelates are limited. In the laboratory, $H$. collusor (Townsend) was shown to have varying flight activity when the wave length of light was changed while the light intensity was kept constant (Dorner \& Mulla 1961). The flight activity of $H$. collusor ceased at wind speeds in excess of $53.6 \mathrm{~m} / \mathrm{min}$. in a laboratory chamber. $H$. collusor preferred low relative humidity at low temperatures and high relative humidity at high temperatures under laboratory conditions (Dorner \& Mulla 1962). The average number of $H$. flavipes Loew observed in the field was reduced $82 \%$ when the wind increased from $0-91 \mathrm{~m} / \mathrm{min}$. to $92-213 \mathrm{~m} / \mathrm{min}$. No $H$. flavipes were caught at wind speeds over $213 \mathrm{~m} / \mathrm{min}$. (Kumm 1935).

Large variations in collections from humans have been observed in conjunction with field experiments. However, there has been no exhaustive study of the attractiveness of human bait to eye gnats under varying environmental conditions.

${ }^{1}$ This research was supported in part by training grant ES00069 from the National Institute of Environmental Health Sciences. Paper No. 3693 of the Journal Series of the North Carolina State University of the Agricultural Experiment Sation.

${ }^{2}$ Predoctoral Trainee and Professor, respectively, Department of Entomology, North Carolina State University, Raleigh, N.C. 27607 , U.S.A.
Therefore, this investigation was conducted to determine what physical environmental conditions must exist before $H$. pusio will become active and be attracted to man. In addition, the variation in flight activity due to the changes in the physical environment that occur in the course of a day were analyzed in relation to human bait.

\section{MATERIALS AND METHODS}

Field temperature measurements were made with a YSI ${ }^{\circledR}$ Model 47 Scanning Tele-Thermometer ${ }^{3}$ and recorded on a YSI Model 80 Laboratory Recorder. The heat sensitive elements were YSI \#401 thermistor probes. This combination of instruments automatically scanned and recorded the temperature at selected locations in the field. The probes were placed at 0.1 and $2 \mathrm{~m}$ above the ground in an open sunlit area and in an adjacent shaded area. The temperature was measured successively at each of the 4 locations every $8 \mathrm{~min}$. during the course of the day. None of the probes were shielded from the direct sunlight. All temperatures were recorded in degrees Celsius.

Light was measured and recorded in the field with an automatic recording photometer (Berry \& Raney 1968). A 2-channel recorder (Rustrak ${ }^{\circledR}$ Model 291 $)^{4}$ permitted simultaneous recording from 2 photosensitive elements (Clairex CL505L) ${ }^{5}$. Both photosensitive cells were placed at $2 \mathrm{~m}$ above the ground, 1 in the open sunlight and the other in the shaded area. Recording was continuous and in foot-candles.

Atmospheric moisture was determined by taking wet and dry bulb temperatures with a Model 566-2 Bendix Psychron ${ }^{\circledR}{ }^{6}$ This portable, electrically aspirated psychrometer with shaded mercury in glass thermometers provided quick and accurate readings. Wet and dry bulb temperatures were taken immediately after each gnat collection at 0.1 and $2 \mathrm{~m}$ above the ground.

Wind speed was measured with a No. 03AM680

${ }^{3}$ Yellow Springs Instrument Co., Inc., Yellow Springs, Ohio 45387.

${ }^{4}$ Rustrak Instrument Div., Manchester, N. H. 03103.

${ }^{5}$ Clairex Electronics, Mt. Vernon, N. Y. 10551.

${ }^{6}$ Bendix Environmental Science Division, Baltimore, Md. 21204. 
TABLE 1. List of parameters and corresponding symbols used in the multiple regression analysis.

\begin{tabular}{ll}
\multicolumn{1}{c}{ PARAMETER } & \multicolumn{1}{c}{ SYMBOL } \\
\hline Temperature & TEMP \\
Temperature $\times$ Temperature & STEMP \\
Temperature $\times$ Vapor Pressure Deficit & TVPD \\
Temperature $\times$ Wind $\times$ Vapor Pressure Deficit & TWV \\
Wind & WIND \\
Temperature $\times$ Wind & TW \\
Wind $\times$ Wind & SWIND \\
Wind $\times$ Vapor Pressure Deficit & WVPD \\
Vapor Pressure Deficit & VPD \\
Vapor Pressure Deficit $\times$ Vapor Pressure Deficit & SVPD \\
Reciprocal of the Vapor Pressure Deficit & RVPD \\
Relative Humidity & RH \\
Relative Humidity $\times$ Temperature & TRH \\
Relative Humidity $\times$ Wind & RHW \\
Temperature $\times$ Wind $\times$ Relative Humidity & TWRH \\
Temperature $\times$ Reciprocal of Vapor Pressure Deficit & TRVPD \\
Wind $\times$ Reciprocal of Vapor Pressure Deficit & WRVPD \\
Wind $\times$ Wind $\times$ RVPD & SWRVPD \\
Temperature $\times$ Wind $\times$ Wind & TSWIND \\
Light & LIGHT \\
Square Root of Light & ROOTLI \\
\hline
\end{tabular}

Slow Speed Anemometer ${ }^{7}$ (range 6 to $300 \mathrm{~m} / \mathrm{min}$.) at the same time and place as the wet and dry bulb readings.

Two adult male humans were used as bait for collecting the gnats. The subjects sat on the ground across from each other and collected the gnats that came to them with a portable vacuum aspirator modified from a hand vacuum cleaner. The collection periods were $5 \mathrm{~min}$. and made every $15 \mathrm{~min}$., with the subjects moving alternately between the sun and the shade. Collections usually started at $0530 \mathrm{EST}$ and continued for 12-14 hr. The gnats were collected in vials and taken to the laboratory for counting and identification.

The analysis of the data for $H$. pusio was made

TABLE 2. Significant parameters and results of statistical analysis.

\begin{tabular}{|c|c|c|c|}
\hline PARAMETER & $\begin{array}{c}\text { DEGREes } \\
\text { OF } \\
\text { FREEDOM }\end{array}$ & $\begin{array}{l}\text { REGRESSION } \\
\text { COEFFICIENT }\end{array}$ & F statistic \\
\hline TEMP & 1 & 1.56433890 & $30.989 * * *$ \\
\hline STEMP & 1 & -0.02319868 & $24.795 * * *$ \\
\hline LIGHT & 1 & -0.00098668 & $25.283 * * *$ \\
\hline ROOTLI & 1 & 0.11412915 & $24.347 * * *$ \\
\hline RVPD & 1 & -0.00129163 & $10.311 * *$ \\
\hline SWIND & 1 & -0.00014028 & $4.503^{*}$ \\
\hline Error & 242 & & \\
\hline $\begin{array}{r}\text { Multiple } \\
* * * \mathrm{P}<0.0 \\
* * \mathrm{P}<0.0 \\
* \mathrm{P}<0.0\end{array}$ & rrelation & ficient $\left(\mathrm{R}^{2}\right)=$ & $195 * * *$ \\
\hline
\end{tabular}

${ }^{7}$ G. M. Mfg. \& Instrument Corp., 2417 Third Avenue, New York, N. Y. 10451.

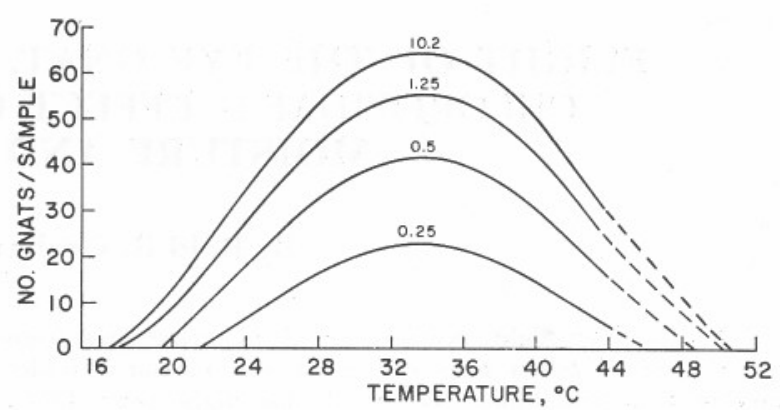

FIG. 1. Response to temperature at 4 vapor pressure deficits $(\mathrm{mm} \mathrm{Hg})$.

from collections on 8, 17 and 21 Sept. 1970 and 20 July, and 2 and 10 Aug. 1971. All collections were made on an unused portion of a golf tee (sun area) and adjoining stand of longleaf pines (shade area) in Whispering Pines, Moore Co., N. C. The data were analyzed by multiple regression using a standard statistical program (Barr \& Goodnight 1971) on the Research Triangle IBM 360/165 computer. The $\sqrt{\mathrm{x}+1}$ transformation was used on the dependent variable $(H$. pusio $)$ to stabilize the variance. TABLE 1 contains a list of the parameters used in the analysis and their symbols which will be used in the text.

All of the parameters (independent variables) shown in TABLE 1 were used in the regression analysis of the dependent variable. The final regression model was arrived at by reducing the number of independent variables. This was accomplished by the step down method; i.e., variables with the most non-significant partial regression coefficients were rejected. The analysis was repeated several times, each time eliminating more non-significant variables, until only significant variables were left in the model.

\section{RESULTS AND DISCUSSION}

TABLE 2 gives the results of the analysis. All of the 4 basic environmental factors (temperature, light, vapor pressure deficit and wind) contributed significantly to the change in the flight activity of

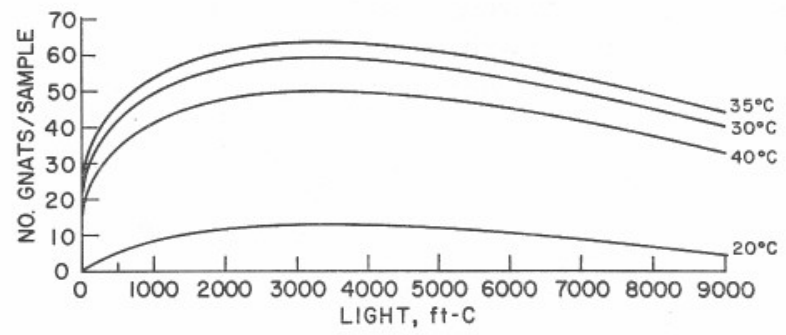

FIG. 2. Response to light at selected temperatures. 
H. pusio. FIG. 1-6 illustrate the influences of these factors on the flight activity of the gnats in relation to human bait. When an environmental factor is not noted on a graph, the value of that factor was the average for the entire experiment [temp. $30^{\circ} \mathrm{C}$, light 4047.9 milliphots (3762 ft-c), VPD $10.2 \mathrm{~mm} \mathrm{Hg}$ and wind $30 \mathrm{~m} / \mathrm{min}$.]. Except where specifically noted, only the ranges of the environmental data gathered in the field are represented in FIG. 1-6.

Temperature. FIG. 1 shows the change in flight activity with increase in temperature at selected vapor pressure deficits. Maximum activity was observed at about $34^{\circ} \mathrm{C}$. The predicted minimum temperatures at which flight is initiated corresponded closely to field observations. These minimums were between $17^{\circ} \mathrm{C}$ and $21.5^{\circ} \mathrm{C}$ at the VPD values that are likely to occur at that time in the morning. The maximum temperatures at which flight would cease were calculated to be between $46^{\circ} \mathrm{C}$ and $50.5^{\circ} \mathrm{C}$ depending on the VPD. These values are extrapolations from the regression equation since $44^{\circ} \mathrm{C}$ was the highest temperature recorded in the field.

Light. Both high and low light intensities decrease flight activity (FIG. 2). When the temperature was $20^{\circ} \mathrm{C}$, there had to be 48.4 milliphots (45 ft-c) of light for flight to occur (FIG. 3). According to the regression equation, flight should occur at 1.076 milliphots ( $1 \mathrm{ft}-\mathrm{c})$ when the temperature is $25^{\circ}$ or higher. This did not agree with field observations. When other factors permitted flight, activity ceased at about 5.38 milliphots $(5 \mathrm{ft}-\mathrm{c})$. This was not reflected in the model because the regression coefficients for LIGHT and ROOTLI were calculated to fit all observations, the vast mjority of which were not near the limiting

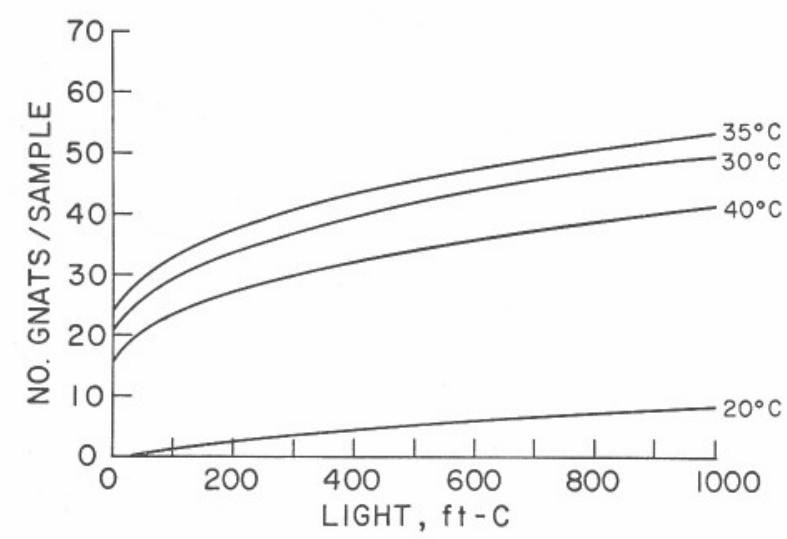

FIG. 3. Response to the lower levels of light at selected temperatures.

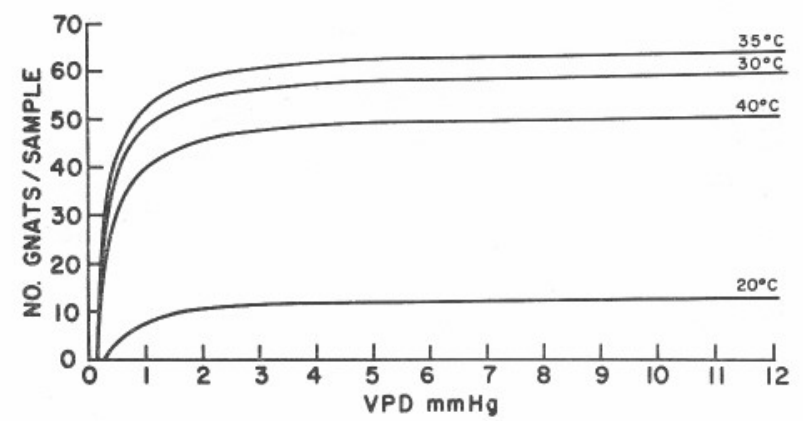

FIG. 4. Response to VPD at selected temperatures.

point for light.

On most days in North Carolina, light is not the limiting factor in the morning. By the time the temperature and VPD allow any activity, the light is considerably above the threshold level. However, in the evening it is usually the light which causes the activity to cease, because the temperature and VPD remain well within the zone of activity when flight activity ceases for the day. The rapid drop in flight activity at the lower levels of light [2152 milliphots (2000 ft-c) and below] supports the field observations that the activity remains high in the late afternoon hours.

According to the regression equation, there is a theoretical upper limit of light intensity at which flight activity will cease, but that level is unrealistically high.

Vapor pressure deficit. The analysis of atmospheric moisture was more difficult to interpret than the others, due to the different ways of measuring it. Relative humidity was found to be a particularly poor estimator of the flight activity. The reciprocal of the vapor pressure deficit (RVPD) gave the most significant estimate of all the atmospheric moisture parameters tried.

FIG. 4 shows the effect of vapor pressure deficit between $0.0 \mathrm{~mm} \mathrm{Hg}$ and $12.0 \mathrm{~mm} \mathrm{Hg}$. Many measurements in excess of $12.0 \mathrm{~mm} \mathrm{Hg}$ were made, but the regression equation indicates that there was only an increase of 1 gnat between 12.0 and $20.0 \mathrm{~mm} \mathrm{Hg}$. As shown in the graph, the effect of this parameter was greatest at low levels. A slight increase in VPD between 0.25 and $3.0 \mathrm{~mm} \mathrm{Hg}$ resulted in a large increase in the flight activity. No activity was predicted at $0.0 \mathrm{~mm} \mathrm{Hg}(100 \%$ saturation). This was confirmed by several field observations indicating no gnat activity at $100 \%$ vapor saturation regardless of the temperature.

Wind. The predicted effect of wind is shown in FIG. 5. The wind often changed rapidly during the course of a single 5-min. collection period, thus 


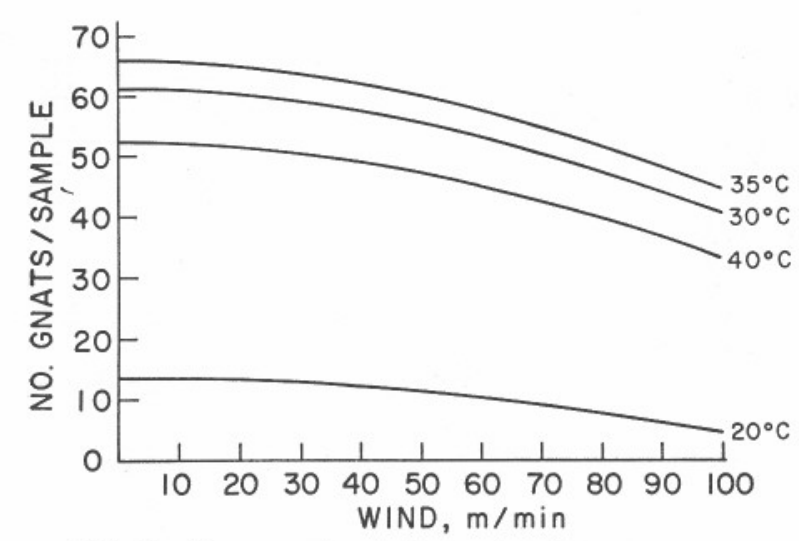

FIG. 5. Response to wind at selected temperatures.

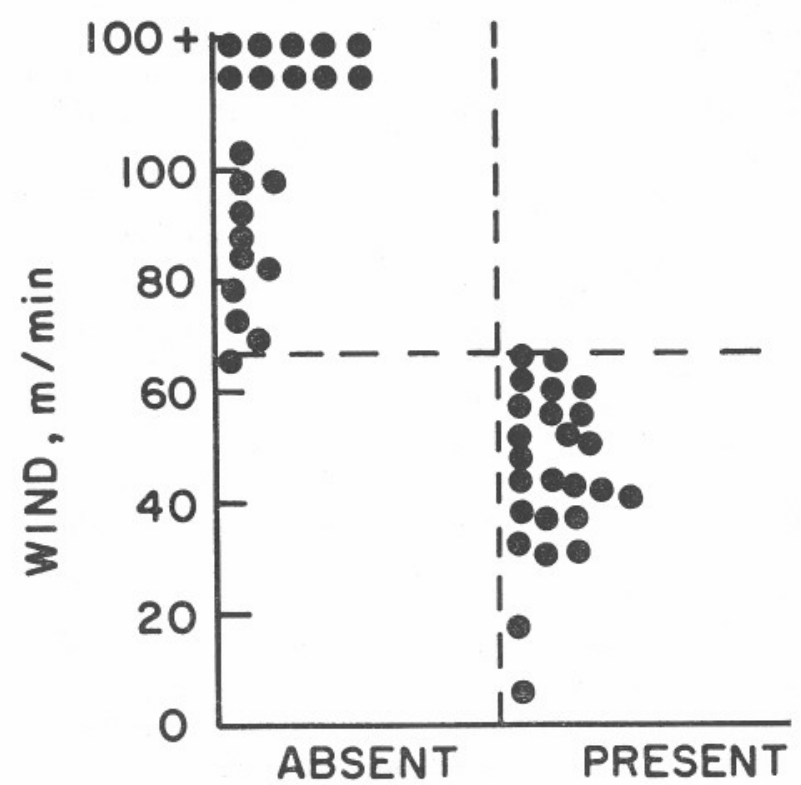

FIG. 6. Presence or absence of flight of $H$. pusio at various wind speeds. Each dot represents 1 collection attempt at the corresponding wind velocity.

making it the least reliable of the environmental measurements. We believe the prediction to be fairly accurate at the low levels of wind speed, but it does not reflect the true response at the higher levels. In response to this shortcoming, a supplementary experiment was designed to determine the maximum wind velocity at which flight occurs. One person observed whether or not $H$. pusio was flying about him; the other made continuous wind measurements for periods of $2 \mathrm{~min}$. Only those observation periods that had relatively constant wind speeds were used. The results of this experiment are shown in FIG. 6. Flight activity was reduced considerably above $50 \mathrm{~m} / \mathrm{min}$., but was observed at wind speeds up to and including 66 $\mathrm{m} / \mathrm{min}$. No flight activity was observed at wind speeds above $68 \mathrm{~m} / \mathrm{min}$. We believe the true response to wind is a combination of these 2 graphs (FIG. 5, 6). Low to medium wind speeds (0-50 $\mathrm{m} / \mathrm{min}$.) result in slight reduction in activity. Above $50 \mathrm{~m} / \mathrm{min}$. the activity drops rapidly to zero.

According to these data, certain physical environmental conditions must exist before $H$. pusio is attracted to man. The temperature must be above $17^{\circ} \mathrm{C}$, the vapor pressure deficit must be $0.25 \mathrm{~mm} \mathrm{Hg}$ or greater, the light above $5.38 \mathrm{mil}$ liphots (5 ft-c) and the wind below $67 \mathrm{~m} / \mathrm{min}$. These constitute the threshold values for flight activity in relation to human bait. The flight activity can be predicted in relation to changes in the temperature, light, vapor pressure deficit and wind.

\section{LITERATURE CITED}

Axtell, R. C. \& T. D. Edwards. 1970. Seasonal populations of Hippelates gnats (Diptera: Chloropidae) in North Carolina. Ann. Ent. Soc. Amer. 63: 1049-53.

Barr, A. J. \& J. H. Goodnight. 1971. Statistical analysis system. Student Supply Store, North Carolina State University Raleigh, N.C.

Berry, R. E. \& L. W. Raney. 1968. A recording photometer for biological studies. Ecology 49: 161-62.

Dorner, R. W. \& M. S. Mulla. 1961. Response of the eye gnat Hippelates collusor to light of different wave lengths. Ann. Ent. Soc. Amer. 54: 69-72.

1962. Laboratory study of wind velocity and temperature preference of Hippelates eye gnat. Ann. Ent. Soc. Amer. 55: 36-39.

Dow, R. P. \& V. D. Hines. 1957. Conjunctivitis in southwest Georgia. Pub. Hlth Rept. 72: 441-48.

Kumm, H. W. 1935. Annual report-Entomological studies made for the Jamacia Yaws Commission during 1934. Rept. Jamacia Yaws Commission for 1934: 19-30.

Roberts, R. H. 1968. A feeding association between Hippelates (Diptera: Chloropidae) and Tabanidae on cattle: Its possible role in transmission of anaplasmosis. Mosquito News 28: 236-37.

Sanders, D. A. 1940. Musca domestica and Hippelates fliesVectors of bovine mastitis. Science 92: 286. 